\title{
Understanding Sprint-Cycling Performance: The Integration of Muscle Power, Resistance, and Modeling
}

\author{
James C. Martin, Christopher J. Davidson, \\ and Eric R. Pardyjak
}

\begin{abstract}
Sprint-cycling performance is paramount to competitive success in over half the world-championship and Olympic races in the sport of cycling. This review examines the current knowledge behind the interaction of propulsive and resistive forces that determine sprint performance. Because of recent innovation in field power-measuring devices, actual data from both elite track- and road-cycling sprint performances provide additional insight into key performance determinants and allow for the construction of complex models of sprint-cycling performance suitable for forward integration. Modeling of various strategic scenarios using a variety of field and laboratory data can highlight the relative value for certain tactically driven choices during competition.
\end{abstract}

Key Words: exercise performance, physical performance, sport, sport physiology, biomechanics, anaerobic

Of the 28 world-championship races governed by the Union Cycliste Internationale (UCI), 8 are all-out sprint events (men's and women's sprint, 500/1000-m time trial, Keirin, and BMX), 4 are often decided in the finishing sprint (men's and women's road race and scratch race), and 2 require repeated sprints (men's and women's points race). Thus, sprint performance is a major determinant of most world-championship racing events. Ultimately, sprint performance represents equilibrium of propulsive power and resistance. In this article, we will review factors that influence maximal cycling power and cycling resistance and the limited investigations exploring sprint-bicycling performance. Sprint-performance articles are quite limited because devices that accurately quantify power during actual bicycling have only recently been developed and validated. Finally, we will integrate aspects of muscle power and resistance in the context of sprint performance.

\section{Aspects of Muscle Power}

Maximal cycling power mainly depends on pedaling rate, muscle size, musclefiber-type distribution, cycling position, and fatigue. Several investigators have

Martin and Davidson are with the Dept of Exercise and Sport Science, and Pardyjak, the Dept of Mechanical Engineering, University of Utah, Salt Lake City, Utah 84112-0920. 
reported quadratic power-pedaling rate relationships for maximal cycling. ${ }^{1-5}$ The apex of that relationship is generally reported to occur at $\sim 120$ to $130 \mathrm{rev} /$ $\min ^{1,2}(\mathrm{rpm})$, and power can vary by up to $25 \%$ within a range of pedaling rates from 60 to $120 \mathrm{rpm}$, demonstrating the importance of this relationship (Figure 1). Furthermore, maximal power is highly impulsive, and instantaneous power within each cycle can be up to $185 \%$ of power averaged over the entire cycle $\left(\mathrm{P}_{\mathrm{REV}}\right)$. The highest values reported in the literature for power averaged over the entire cycle are over $2500 \mathrm{~W}{ }^{6}$

Although pedaling rate is the most common velocity term for describing cycling, it actually constrains 2 physiological phenomena. Pedaling rate, in conjunction with crank length, determines pedal speed and thereby sets shortening velocity for uniarticular muscles that span the hip, knee, and ankle. ${ }^{7,8}$ Shortening velocity is well known to influence muscle power': Power will initially increase with increasing shortening velocity, reach a maximum, and then decrease with further increases in shortening velocity. In addition, pedaling rate, per se, sets the time within which muscles must become excited, produce force while shortening, and relax before lengthening. This time frame (half the time for a cycle, eg, 250 milliseconds at 120 $\mathrm{rpm}$ ) reduces muscle force and power via excitation-relaxation kinetics. ${ }^{7,10,11}$ Are both of these mechanisms, shortening velocity and excitation-relaxation kinetics, important? Martin and colleagues ${ }^{7,12}$ have shown that the interaction of pedaling rate and pedal speed constrains maximal cycling power across a broad range of pedaling rates, pedal speeds, and crank lengths. Consequently, cycling power is governed by the interaction of shortening velocity and excitation. ${ }^{713} \mathrm{~A}$ tangential

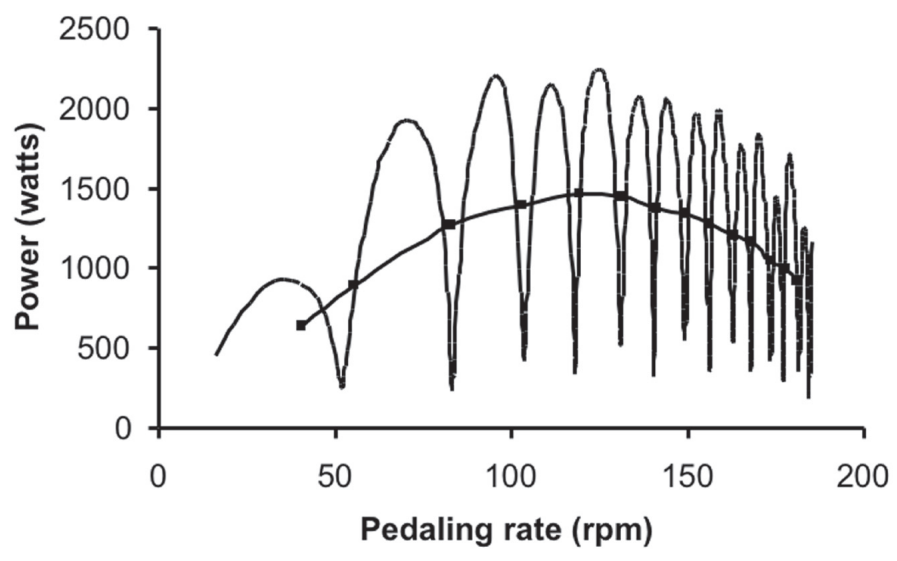

Figure 1 - Power-pedaling rate relationship. Data from a representative subject performing an inertial-load power test show instantaneous power $\left(\mathrm{P}_{\mathrm{I}}-\right)$ and power averaged over each complete revolution of the pedal cranks $\left(\mathrm{P}_{\mathrm{REV}}-\mathrm{v}-\right)$ in relation to pedaling rate (rpm). The pedaling rate at which subjects reach a maximum value for $\mathrm{P}_{\mathrm{REV}}$ is defined as optimal pedaling rate. Note that $\mathrm{P}_{\mathrm{I}}$ varies within each pedal revolution and reaches values up to $85 \%$ greater than $\mathrm{P}_{\text {REV }}$. 
finding in those studies was that cycle crank length was not a significant factor during maximal efforts over the range of commercially available equipment (165 to $180 \mathrm{~mm}) .{ }^{12}$ Indeed, only large variations $(50 \mathrm{~mm})$ in crank length lead to small but significant differences in the ability to produce maximal power.

Ultimately, cycling power must be produced by muscles that span the hip, knee, and ankle. Power produced at each of those joints has not been reported in peer-reviewed articles, but McDaniel et $\mathrm{al}^{14}$ have reported such data in an abstract. Their data show that, during maximal seated isokinetic cycling at $120 \mathrm{rpm}, 49 \%$ of the power delivered to the pedal was produced at the knee, $32 \%$ was produced at the hip, $9 \%$ was produced at the ankle, and 9\% was transferred across the hip. This warrants more research, and we are currently pursuing this in our laboratory.

Because most cycling power is produced at the knee and hip, it might reasonable to expect that muscle mass about those joints influences maximal power. Recent muscle-functional magnetic-resonance-imaging data showed that vastus lateralis and vastus medialis volume accounted for $70 \%$ of the variance in measured maximal power during repeated 6-second sprints. ${ }^{15}$ Similarly, lean thigh volume $\left(r^{2}=.86\right)^{1}$ and lower limb volume $(r=.92)^{16}$ have been reported to be highly predictive of maximal power. Clearly, increased muscle mass will increase the power produced by a muscle of any specific fiber-type distribution. In addition, fiber-type distribution dramatically alters maximal in situ muscle power. Muscles with predominantly fast-twitch fibers exhibit higher maximum and optimal shortening velocities and are up to 5 times as powerful (per unit muscle mass) as slow-twitch muscles. ${ }^{17}$ The relationship of optional velocity with fiber type is evident in cycling, as well. Hautier and colleagues ${ }^{18}$ reported that optimal pedaling rate was highly correlated $(r=.88)$ with the proportion of cross-sectional area occupied by type II fibers in vastus lateralis. Similarly, Pearson et $\mathrm{al}^{16}$ reported a high correlation $(r=.80)$ between the percentage of myosin heavy-chain II from a vastus lateralis biopsy and optimal pedaling rate. Taking the combined effects of muscle mass and fibertype distribution a step further, Martin and colleagues ${ }^{19}$ reported that the product of lean thigh volume and optimal pedaling rate (a surrogate marker for fiber-type distribution) accounted for $83 \%$ of the variability in maximal power across the life span (8 to 70 years), whereas lean thigh volume alone accounted for only $76 \%$ of the variability. These data demonstrate that both muscle volume and fiber-type distribution influence maximal cycling power.

During competitive sprinting, cyclists often adopt a standing position during the initial (acceleration) phase and a seated position while at high speed. ${ }^{6}$ Reiser et $\mathrm{al}^{20}$ reported that subjects produced greater power $(\sim 8 \%)$ when performing a 30 -second Wingate anaerobic test in the standing position. Davidson et $\mathrm{al}^{21}$ have observed (in an abstract) a slightly greater (12\%) increase in maximal cycling power during standing in a 3-second inertial-load test. ${ }^{1}$ If power is increased by standing, where does that extra power come from? Davidson and colleagues ${ }^{22}$ reported (in an abstract) that the increased power in the standing position resulted from additional power from the upper body (transferred across the hip). It is interesting that ankle-, knee-, and hip-joint powers did not differ with position in that investigation. These data suggest that, although additional power might be generated in the standing position, the biomechanics of power generation in the leg segments are unchanged. This finding has implications for the positive influence of upper body strength and dynamics during sprinting. 


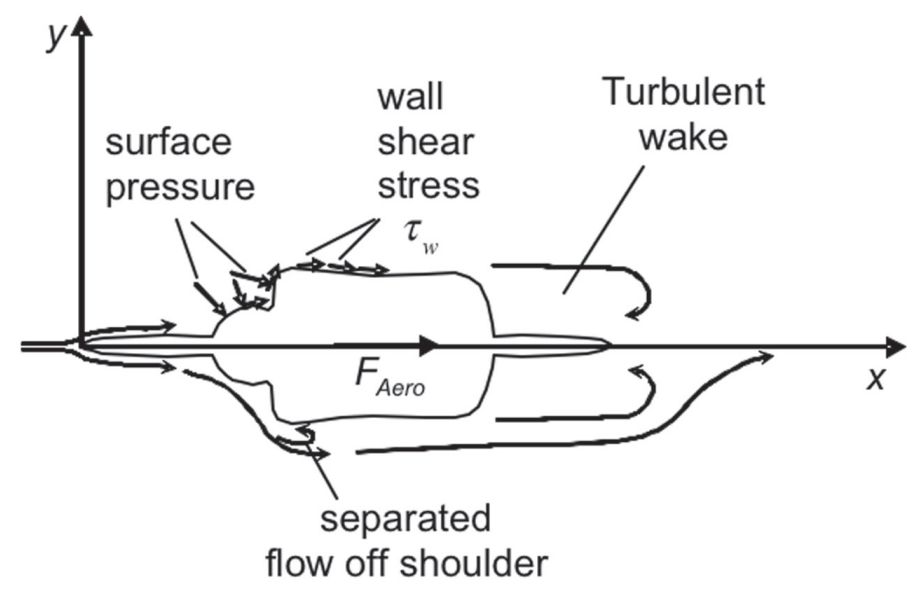

Figure 2 - Schematic illustrating the flow around a cyclist and the surface stresses acting on the rider that produce drag. The highest surface pressures are located at the leading edge of the rider and the lowest pressures are in the wake. Form drag represents the integral of this pressure over the entire surface area. Note that the rider is moving right to left and that the coordinate system moves with the rider.

Thus far, this review has been focused on aspects of maximal power over short durations, which are likely free from fatigue. ${ }^{23}$ Many competitive sprints take place over 10 to 60 seconds, however, wherein power decreases because of fatigue. Furthermore, fatigue can occur both within and between bouts of maximal sprinting and depends on pedaling rate. Perhaps the most commonly reported protocol for evaluating fatigue in a maximal cycling model is the Wingate anaerobic test. ${ }^{24} \mathrm{~A}$ fatigue index is calculated from the maximum value recorded early in the test and the minimum power produced at the end of the test. Normative data for Wingate anaerobic tests indicate that fatigue index was approximately $38 \%$ and $35 \%$ in young adult men and women, ${ }^{25}$ respectively, demonstrating the substantial effect of fatigue. Interpretation of Wingate anaerobic test results is complicated because pedaling rate varies throughout the test. That variability makes it difficult to know how much of the "fatigue index" results from pedaling rate and how much is truly representative of fatigue.

To control for the effects of pedaling rate, some authors have used isokinetic cycling to study fatigue. Jones and colleagues ${ }^{26}$ reported that fatigue was greater when pedaling at $140 \mathrm{rpm}$ than at $60 \mathrm{rpm}$, but total work over 30 seconds did not differ because power at $60 \mathrm{rpm}$ was much lower early in the trial. Similarly, Beelen and Sargeant ${ }^{23}$ reported that cyclists initially produced greater power at higher pedaling rates but experienced greater fatigue at those higher rates. Data from other protocols suggest that maximal efforts of longer duration (3 to 300 seconds) might be influenced by a dependence on anaerobic metabolism. ${ }^{27-29}$ Weyand and colleagues ${ }^{28,30}$ recently presented evidence for an essential metabolic effect on fatigue progression and provided an extremely consistent exponential model of 
fatigue during maximal sprint cycling over times ranging up to 300 seconds. Their model differs from traditional measures of maximal cycling, in that their EMG data show progressive increases in recruitment over the duration of the trials, indicating that maximal effort might have only been achieved at termination of the trial. Between bouts of short duration ( $<4$ seconds) maximal sprinting power has been shown to be highly repeatable and fatigue resistant ${ }^{31-33}$ with some dependence on the recovery interval ${ }^{34,35}$ and activity. ${ }^{36}$ Subsequent maximal sprinting efforts might actually be facilitated by a previous maximal effort ${ }^{33}$; thus the best "warm-up" technique might be extremely task specific. To summarize, the ability to sustain maximal cycling power is limited in duration, with large pedaling-rate-dependent decrements in power beginning within the first few seconds, making fatigue an important consideration for maximal sprint efforts longer than 4 seconds.

Finally, environmental conditions and substrate availability have been shown to influence maximal cycling power. When sprints are repeated over time in stressful environmental conditions, both increases in core and muscle temperature ${ }^{37-39}$ and declining hydration status ${ }^{37}$ reduce maximal power. In contrast, increasing the availability of carbohydrate in blood ${ }^{37,40}$ and muscle ${ }^{41}$ attenuates the decline in maximal power over time. Although significant differences are reported in these studies, it is interesting to note that maximal sprint power was never reduced more than $15 \%$ in any case. Indeed, the ability to maintain maximal power under stressful conditions might be a genetic selection criterion in some species. ${ }^{42}$

\section{Factors That Influence Resistance in Sprint Cycling}

\section{Modeling Approaches}

A number of cycling-performance models have been developed and are widely used. ${ }^{43-46}$ They represent a simplified equation for the conservation of energy in rate form; hence they are time-dependent balances between power production, power sinks, and changes in energy states. Including time-dependent terms in modeling sprint performance is critical because of the dynamic nature of sprinting. In this section, we will use the model of Martin et $\mathrm{al}^{45}$ to exemplify the various aspects of modeling sprint-cycling power. First, we will present the basic principles of the model.

The basis for a cycling-performance model is Newton's second law of motion applied to a cyclist, namely,

$$
\sum \vec{F}=m_{T} \vec{a}_{B}=m_{T} \frac{d \vec{V}_{B}}{d t}
$$

where $m_{T}$ is the total mass of the rider and bicycle combined and $\vec{a}_{B}$ and $\vec{V}_{B}$ are the acceleration and velocity vectors of the bicycle with respect to the ground. Many forces act on the rider-bicycle combination, but the system is dominated by

$$
\sum \vec{F}=\vec{F}_{T}+\vec{F}_{\text {Aero }}+\vec{F}_{R R}+\vec{F}_{B R}+\vec{F}_{G}
$$

Here, $\vec{F}_{T}$ is the available force supplied to the pedals by the rider; $\vec{F}_{A e r o}, \vec{F}_{D D}$, and $\vec{F}_{B R}$ are the aerodynamic, rolling-resistance, and bearing-resistance forces acting against 
the rider; and is $\vec{F}_{G}$ the gravitational force. Equation 1 is a vector equation; hence, it represents 3 equations in a Cartesian coordinate system. The 3 equations can be collapsed into a single useful scalar mechanical-energy equation for the performance of a cyclist by taking the dot product of Equation 1 with $\vec{V}_{B}$ as follows:

$$
\begin{gathered}
\left.\vec{V}_{B} \oint m_{T} \frac{d \vec{V}_{B}}{d t}=\vec{F}_{T}+\vec{F}_{\text {Aero }}+\vec{F}_{R R}+\vec{F}_{B R}+\vec{F}_{G}\right) \\
m_{T} \frac{d\left(V_{B}^{2} / 2\right)}{d t}=\vec{F}_{T} \diamond \vec{V}_{B}+\vec{F}_{\text {Aero }} \diamond \vec{V}_{B}+\vec{F}_{R R} \diamond \vec{V}_{B}+\vec{F}_{B R} \diamond \vec{V}_{B}+\vec{F}_{G} \Delta \vec{V}_{B} \\
m_{T} \frac{d\left(V_{B}^{2} / 2\right)}{d t}=\dot{W}_{T}+\dot{W}_{\text {Aero }}+\dot{W}_{R R}+\dot{W}_{B R}+\dot{W}_{G}
\end{gathered}
$$

Equation 3 is an expression for the time rate of change of the mechanical (kinetic) energy associated with cycling $(\dot{E})$. The available power $\left(\dot{W}_{T}\right)$ is some fraction of the total energy rate expended by the athlete. It is related to the efficiency of the rider ${ }^{43}$ and represents a source term in Equation 3. The terms $\dot{W}_{\text {Aero }}, \dot{W}_{R R}$, and $\dot{W}_{B R}$ are sinks energy associated with aerodynamic, rolling, and bearing resistance. The last term in Equation $3\left(\dot{W}_{G}\right)$ is a potential energy term and can be either a source or a sink depending on whether the rider is sprinting uphill or downhill. This term represents the work rate associated with lifting the rider and bicycle mass.

Imbalances in the terms on the right-hand side of Equation 3 lead to increases or decreases in rider velocity that are reflected in $\dot{E}$. For example, at the start of a sprint, $\dot{W}_{T}$ is greater than any of the resistance terms and results in rider acceleration and increased kinetic energy. Later in the review, we discuss the ramifications of this on sprint performance. In the following section, the details of each of the elements of Equation 3 are reviewed, and simplified models are presented. Useful modeling simplifications that are not covered here can be found elsewhere. ${ }^{43,44}$

\section{Fundamentals of Aerodynamic Drag}

When a cyclist is traveling over a flat surface at steady state, aerodynamic drag has been shown to account for up to $96 \%$ of his or her available power. ${ }^{45}$ The aerodynamic $^{2}$ forces acting on a cyclist can be decomposed into 3 components associated with a Cartesian coordinate system fixed to the rider, as show in Figure 2. The net aerodynamicforce component acting in the direction of travel is known as aerodynamic drag. Formally, the drag force $\left(F_{\text {Aero }}\right)$ is obtained by integrating the total surface stress $(\bar{\tau})$ over the surface area of the bicycle-cyclist $\left(A_{S}\right)$ combination, namely,

$$
\vec{F}_{\text {Aero }}=\int_{A_{S}} \vec{\tau} \diamond \hat{x} d A_{S}
$$

where $\hat{x}$ is the unit vector opposite the direction of travel as shown in Figure 2. The total surface stress is usually separated into the dominant surface stresses acting parallel $\left(\vec{\tau}_{w}\right)$ and normal $(p)$ to the surface,

$$
\vec{F}_{\text {Aero }}=\int_{A_{S}} \vec{\tau}_{w} \cdot \hat{x} d A_{S}-\int_{A_{S}}(p \cdot \hat{n}) \cdot \hat{x} d A_{S}
$$




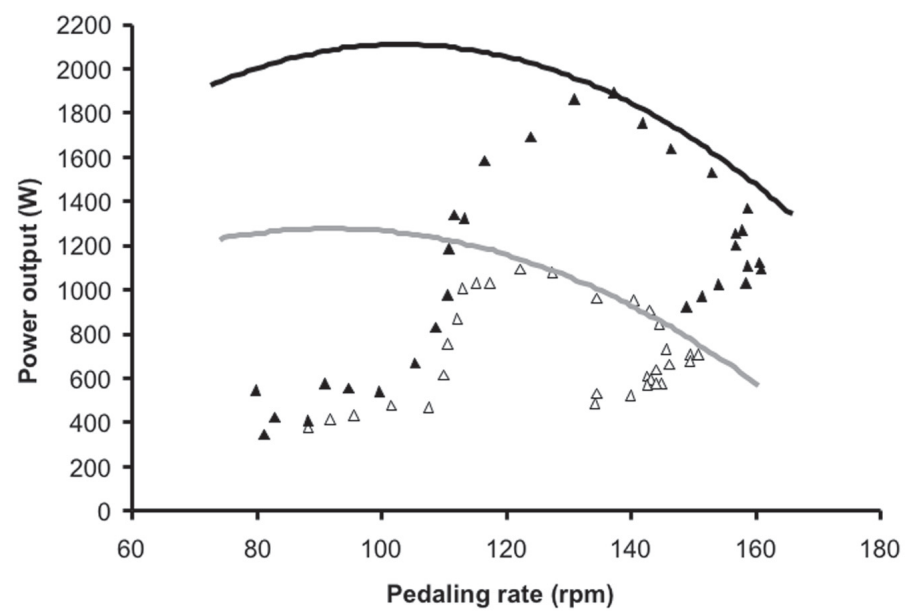

Figure 3 - Mean power output and pedaling rate for men $(\mathrm{n}=4, \backslash \mathrm{BITri})$ and women (n $=4, \Delta$ ) during a $200-\mathrm{m}$ time trial. The data represent average power produced every second by men and women and the corresponding pedaling rate. Within the time trial, cyclists accelerated gradually for the first 5 to 7 seconds and then initiated maximum acceleration. The parabolic curves represent the average predicted maximal power output (based on the linear torque-pedaling rate regression) that could be produced in the range of pedaling rates 75 to $170 \mathrm{rpm}$ if the athletes were fatigue free. Data points below the parabolic curve represent fatigue. The time trial was performed entirely on the descending limb of the power-pedaling rate curve.

The first term in Equation 5 is usually referred to as skin friction, and the second term is called form drag. For flow around objects such as cubes, cylinders, and cyclists, pressure drag dominates the total drag. ${ }^{47}$ The flow around a cyclist is mostly turbulent, with regions of separated flow and wakes that lead to increased pressure drag.

For a control volume that wraps around the bicycle-cyclist combination, the work rate associated with aerodynamic forces can be written as follows ${ }^{47}$ :

$$
\dot{W}_{\text {Aero }}=\int_{A_{S}} \vec{\tau} \Delta \vec{V}_{W / B} d A_{S}-\vec{V}_{B} \diamond \int_{A_{S}} \bar{\tau} d A_{S}=\vec{F}_{\text {Aero }} \diamond \vec{V}_{B}
$$

where $\vec{V}_{W / B}$ is the velocity of the wind with respect to the moving bicycle and $\vec{V}_{B}$ is the velocity of the bicycle.

Measuring the individual components of drag is very difficult, and the forces are usually lumped together. Because of the large number of independent variables, dimensional analysis is typically employed to reduce the number of experiments that are needed to understand drag. If the atmosphere is assumed to be of constant density for the small region where the bicycle is ridden, the drag force can be written in the functional form $F_{\text {Aero }}=f\left(\rho, \mu, V_{W / B}, L, e, \Phi\right)$, where $\rho$ is the air density (a function of temperature, relative humidity, and barometric pressure ${ }^{48}$ ), $\mu$ is the dynamic viscosity of air (primarily a function of temperature ${ }^{47}$ ), $V_{W / B}$ is the speed of 
the wind with respect to the bike, $L$ is a length scale associated with the bike-rider combination, $e$ is a surface-roughness length scale, and $\Phi$ is the wind angle with respect to the rider. Performing a dimensional analysis of the problem yields the following dimensionless parameters that govern cyclist drag:

$$
C_{D}=\frac{\vec{F}_{\text {Aero }}}{\frac{1}{2} \rho V^{2} A} \quad R_{L}=\frac{V_{W / B} L \rho}{\mu} \quad k=\frac{e}{L} \quad \Phi
$$

where $A\left(\sim L^{2}\right)$ is the projected frontal area of the rider. In the relationships given above, $C_{D}$ is the drag coefficient and represents a nondimensional drag force, $R_{L}$ is the Reynolds number and represents the ratio of inertial to viscous forces, and $k$ is a nondimensional roughness. The functional relationship simplifies to $C_{D}=$ $f\left(R_{L}, k, \Phi\right)$ and is different for any rider position and rider-bicycle combination (ie, aerodynamic shape). This provides a framework for determining the drag force. Most often $C_{D}$ is approximated to be independent of $R_{L}, k$, and $\Phi$. The total drag force is then measured using a drag balance in a wind tunnel. If this is done, the aerodynamic power term can be modeled as

$$
\dot{W}_{\text {Aero }}=V_{B} \frac{\rho V_{W / B}^{2}}{2} C_{D} A
$$

Although many objects have $C_{D}$ s that do not vary much over a wide range of wind speeds (spheres, cylinders, etc), the turbulent low-pressure region in the wake of the body changes significantly with direction. ${ }^{45}$ Kyle ${ }^{49}$ and Zdravkovich et $\mathrm{al}^{50}$ have measured $C_{D}$ using coast-down tests and wind-tunnel tests, respectively. $\mathrm{Kyle}^{49}$ found a relatively constant $C_{D}$ of $\sim 0.8$ over a range of speeds (4.4 to 11.2 $\mathrm{m} / \mathrm{s}$ ) for riders in a racing position (hands on the dropped part of the handle bar, arms stiff, and head up) and slight reductions $\left(C_{D} \approx 1.09\right.$ to 0.92$)$ with increasing speed for a rider standing vertically on the pedals. Zdravkovich et $\mathrm{al}^{50}$ reported smaller $C_{D}$ s than Kyle ${ }^{49}$ but also found very little variation in $C_{D}$ for large Reynolds numbers. As expected, both studies found that $C_{D}$ varied significantly with position and size of riders. Olds et $\mathrm{al}^{48}$ also found lower $C_{D}$ values than Kyle for a track cyclist in the drops by approximately a factor of 2 . The $C_{D}$ values reported by Kyle, ${ }^{49}$ Zdravkovich et al, ${ }^{50}$ and Olds et $\mathrm{al}^{48}$ range from $\sim 0.35$ to 1.1 , with the lowest values for riders in tucked descending and time-trial positions and the largest values for standing on the pedals.

Calculating $C_{D}$ requires estimates of rider frontal area using photographic weighing, ${ }^{43}$ digital photo analysis, ${ }^{51,52}$ or morphometric parameterization. ${ }^{46}$ Great care must be taken to minimize uncertainty in area measurement. To eliminate this difficulty, Martin et al ${ }^{45}$ recommend using $C_{D} A$, or "drag area" (reported in $\mathrm{m}^{2}$ ). Drag area effectively integrates all the effects associated with stresses acting on the rider and is dominated by the turbulence associated with rider position, shape, size, and surface roughness. $C_{D} A$ can be measured in a wind tunnel ${ }^{45}$ or on the road using commercial power meters, ${ }^{6}$ tow tests, ${ }^{43}$ and coast-down tests. ${ }^{49}$ Martin et $\mathrm{al}^{6}$ found that wind-tunnel and field-derived $C_{D} A$ s using power meters did not differ. This finding allowed them to use this field technique to derive $C_{D} A$ s for sprinters in both seated and standing positions.

Drag reduction is of utmost importance to sprint cyclists because hundredths of a second are important in deciding elite-level competitions. Typically, reductions 
are realized by optimizing rider position and equipment if riding alone and positioning (ie, drafting) when riding in groups. Independent drag data on equipment have been presented by Kyle, ${ }^{53}$ Greenwell et al, ${ }^{54}$ Tew and Sayers, ${ }^{55}$ and Martin et al. ${ }^{6,45}$ The aerodynamic benefit of riding in a group of cyclists is more poorly understood. $\mathrm{Kyle}^{49}$ reported an $\sim 33 \%$ reduction in the power required to maintain a specified speed and an $\sim 38 \%$ reduction in wind resistance for riders in a 2-man pace line. These experiments included coast-down tests over a wide range of speeds (24 to 56 $\mathrm{km} / \mathrm{h}$ ) and wheel-to-wheel distances ( $\Delta x \approx 0$ to $2 \mathrm{~m}$ ). Kyle also found no additional reductions for drafting behind additional riders. Zdravkovich ${ }^{50}$ reported similar wind-resistance reductions of $37 \%$ and $35 \%$ for a 2-man pace line with wheelto-wheel distances of 70 and $90 \mathrm{~cm}$, respectively, at $30 \mathrm{~km} / \mathrm{h}$. Using field-derived power measurements for a $4000-\mathrm{m}$ team pursuit at $60 \mathrm{~km} / \mathrm{h}$, Broker et al ${ }^{56}$ reported an $\sim 29 \%$ decrease in the required power for the second rider in the pursuit. They also reported an additional reduction of $7 \%$ in required power for the third rider, with no measurable reductions for the fourth rider. Both Kyle ${ }^{49}$ and Broker et al ${ }^{56}$ allude to the importance of a skill component in drafting to obtain the maximum benefits and that the reductions can vary significantly for less skilled riders.

Complete models regarding drafting are still lacking. Olds et $\mathrm{al}^{48}$ have deduced the following aerodynamic-resistance correction factor caused by drafting by piecing together data sets:

$$
C F_{\text {draft }}=1-0.3835+1.25 \Delta x+0.0405 \Delta x^{2}
$$

Unfortunately, a model that modifies a rider's measured $C_{D} A$ as a function of wheel separation, effective wind angle, and sideways distance in a pace line remains illusive.

\section{Rolling and Bearing Resistance}

The force caused by rolling resistance is related to the weight of the bike and rider, wheel radius, tire pressure, tread pattern, casing construction, and the gradient and texture of the riding surface. Following Olds et al, ${ }^{44}$ the rolling resistance is modeled as the normal force times a coefficient of rolling resistance $\left(C_{R R}\right)$ that includes the effects of tire and surface characteristics. This simplification leads to a model of the form $\dot{W}_{R R}=V_{B} \cos \theta C_{R R} m_{T} g$, where $\theta$ is the local angle of the road surface given by the arctangent of the grade of the road and $g$ is the acceleration of gravity. Kyle ${ }^{53}$ reports rolling resistances for different road and track tires and surfaces ranging from 0.0019 to 0.0040 .

The bearing resistance is typically extremely small ( $2 \%$ to $5 \%$ of total power) and is a function of bearing type, load, and angular velocity of the wheel. ${ }^{53}$ Using the work of Dahn and colleagues, ${ }^{57}$ Martin et $\mathrm{al}^{45}$ estimated the bearing friction for a typical cyclist with cartridge bearings to be

$$
\dot{W}_{B R}=V_{B}\left(91+8.7 V_{B}\right) 10^{-3}
$$

This method is somewhat limited by the ability to find reported data on the exact bearing type used in a bicycle. To address that limitation, Martin et $\mathrm{al}^{6}$ recently combined both rolling and bearing resistance into a single global coefficient of resistance that was determined in the field using multiple linear regression. 


\section{A Field Model}

Combining these simplifications leads to the following useful field model that can be used for steady-state ${ }^{45}$ or sprint cycling 6 :

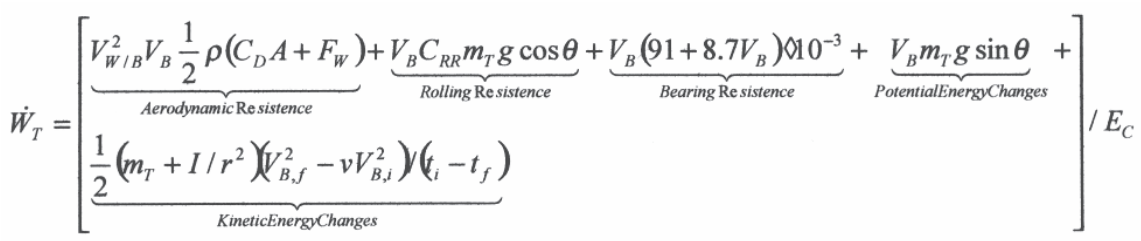

Here, $E_{c}$ is a chain drive efficiency term. As shown in the preceding equation, Martin et $\mathrm{al}^{45}$ add 2 terms related to wheel rotation: an aerodynamic force associated with wheel rotation $\left(F_{w}\right)$ and a wheel-rotation kinetic-energy term $I / r^{2}$, where $I$ is moment of inertia of the wheel.

Martin et $\mathrm{al}^{6}$ have successfully modeled sprint cycling on the track using this methodology. They point out the importance of modeling the corners in the track and including the difference between speed of center of mass of the rider and the wheels because of lean angle. For sprint cycling, additional work remains to be done to further our understanding of the complex changes in the drag area while going from a seated to standing position and in describing drag reductions caused by drafting in a variety of scenarios.

\section{Sprint Performance}

In this final section, studies of sprint-bicycling (as opposed to laboratory-based cycle ergometry) performance and interaction of factors that influence power production and resistance are examined.

Only a few authors have reported measures recorded during actual sprint bicycling. Craig and colleagues ${ }^{27}$ measured cycling power during ergometer tests of 10 to 60 seconds and correlated those measures with $1000-\mathrm{m}$ bicycling-performance time. The only significant predictors of $1000-\mathrm{m}$ performance time were power and work performed in the 60-second ergometer test. They suggested that those results were caused by the increased reliance on aerobic metabolism during the 60 -second tests and the 1000 -m performance. ${ }^{29,30}$ That is, performances of durations greater than 3 seconds are determined by both maximum muscle power and aerobic power. ${ }^{30}$

In a similar investigation, Dorel and colleagues ${ }^{51}$ reported laboratory and competition data of world-class sprint cyclists. Maximum power, normalized by frontal surface area, was significantly correlated with 200 -m performance velocity, suggesting that performance largely depended on the riders' ability to overcome aerodynamic drag. Furthermore, average pedaling rates during the 200-m (155 \pm $3 \mathrm{rpm}$ ) were significantly greater than pedaling rates for maximum power (130 $\pm 5 \mathrm{rpm}$ ). The authors speculated that these cyclists chose smaller gear ratios in competition to optimize power during acceleration. In support of that speculation, Martin and colleagues ${ }^{58}$ reported in an abstract that world-class sprint cyclists performed the entire 200-m time trial on the descending limb of the powerpedaling rate relationship (Figure 3$)$. They reached pedaling rates $(163 \pm 3 \mathrm{rpm}$ ) that 
would reduce power by approximately $35 \%$ at maximum speed. Finally, Gardner and colleagues ${ }^{59}$ recorded power during national and international competition and reported that elite sprint cyclists produced peak power values of $1939 \pm 241 \mathrm{~W}$ during match sprint competitions. Peak power was produced at pedaling rates of $130 \pm 10 \mathrm{rpm}$, and the cyclists reached peak pedaling rates of $161 \pm 3 \mathrm{rpm}$. Thus, both the aerodynamic and acceleration terms are critical for 200-m bicycling performance, and selected gear ratios might represent a compromise between the need for power during acceleration and at maximum speed. In addition, the aerobic contribution to sprint performances can be significant. Although frontal area is an important predictor of average velocity, aerodynamic-drag area should be even more predictive. Instantaneous measures of power and speed would provide additional insight into performance power.

Recently, Martin and colleagues ${ }^{6}$ reported that aerodynamic-drag area and rolling resistance could be accurately determined from field bicycling trials with power measurement. Those field-based parameters were then used to model sprintbicycling speed by forward integration. Although the focus of that article was the modeling technique, the data represented maximal performances from a standing start by world- and Olympic-champion athletes. Furthermore, this model allows calculation of the power associated with acceleration and aerodynamic drag throughout each performance and can be used to determine the relative importance of those resistance terms. Qualitatively, more power is likely associated with acceleration at the start, whereas at high speed more power is associated with aerodynamic drag.

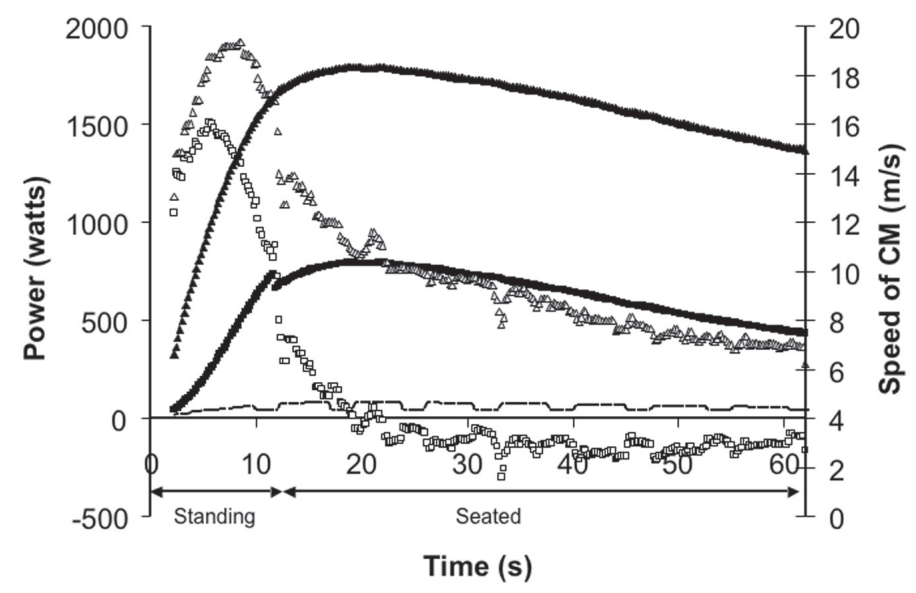

Figure 4 - Power, resistance, and energy changes during a 1000-m time-trial performance of a world-champion cyclist. Speed (BITril) represents the speed of the center of mass, which does not vary in the turns as does wheel speed. In the first few seconds, power $(\Delta)$ increased and then decreased, reflecting the power-pedaling rate relationship. Changes in kinetic energy $(\square)$ required most of the generated power for the first 12 seconds, whereas aerodynamic resistance $(v)$ dominated thereafter. The discontinuity in aerodynamic-drag power represents the standing-to-seated transition. After 21 seconds, the rider slowed and energy was negative, meaning that stored kinetic energy was being given up to do external work. Rolling resistance power (- $)$ varied because of increased normal force in the turns. 
To our knowledge, however, no authors have addressed this issue quantitatively. It might be useful to reexamine these data to determine the power required for acceleration and aerodynamic drag during a 1000-m time trial (Figure 4). Within the first 12 seconds, power increased to a maximum and then decreased, reflecting the power-pedaling rate relationship and possibly some early fatigue. Acceleration required 73\% of the work over the first 12 seconds. By 12 seconds this 1000-m time-trial cyclist had exceeded $17 \mathrm{~m} / \mathrm{s}$, and aerodynamic drag dominated the power requirement from then until the end of the performance, accounting for $74 \%$ of total work. Twelve seconds was also when the cyclist transitioned from standing to seated cycling. Speed increased until 17 seconds even though power had decreased substantially. From 17 to 21 seconds, speed was nearly constant, indicating that power production and resistance were matched. Beyond 21 seconds, the cyclist began to slow, and thus $\dot{E}$ was negative, indicating that kinetic energy was being given up to do external work. Consequently, $\dot{E}$ accounted for only $17 \%$ of work for the entire performance. Rolling resistance accounted for $9 \%$ of total work, which was surprising given the low $C_{R R}(0.24 \%)$. This relatively high contribution resulted partially from the increased normal force in the curves. The standing-start nature of the 1000-m time trial dictates that substantial work must be associated with acceleration. Other sprinting performances, such as road-race finishes, are initiated from high speed and likely require less acceleration work.

To date, no authors have reported power data for a finishing sprint in a professional road race; however, we recently obtained data from the winner of a road stage in a major national tour and UCI "pro tour" event (Figure 5). The final maximal effort was 14 seconds in duration, during which average power was $926 \mathrm{~W}$ and peak power was $1097 \mathrm{~W}$. In the final sprint the cyclist accelerated from 58.2 to 65 $\mathrm{km} / \mathrm{h}(16.2$ to $18.1 \mathrm{~m} / \mathrm{s})$, indicating an increase in kinetic energy of $2586 \mathrm{~J}$ (total mass was $80 \mathrm{~kg}$ ). During this period, total work was $12,960 \mathrm{~J}$, and, consequently, inertial power represented $20 \%$ of total work output (184 W for 14 seconds). Assuming $C_{R R}=0.4 \%$, rolling resistance required $54 \mathrm{~W}$, and $688 \mathrm{~W}(74 \%$ of power during the finishing sprint) remained to overcome aerodynamic resistance. This power indicates a drag area of approximately $0.288 \mathrm{~m}^{2}$, suggesting that the rider was in a good aerodynamic position considering he used traditional handlebars. ${ }^{60}$ Thus, in this UCI pro-tour wining sprint, the rider's power was distributed as $74 \%$ for aerodynamic resistance, $20 \%$ for $\dot{E}$, and $6 \%$ for rolling resistance. As a final comment, the peak power of $1097 \mathrm{~W}$ might seem modest compared with the power reported for track cyclists over short distances. This power, however, won a major professional road stage race with a large peloton intact. It was produced after 5 and a half hours of racing and was the culmination of several kilometers of increasing speed in approaching the finish line. During the final 3 minutes, this cyclist averaged $490 \mathrm{~W}$ and exceeded $600 \mathrm{~W}$ for 64 seconds. Thus, this performance represents an extremely high standard for professional road-sprinting power.

Other factors interactively influence power production and resistance. Standing to pedal increases power output $8 \%$ to $12 \%{ }^{20,21}$ and aerodynamic-drag area by $24 \% .^{6}$ What if the road cyclist described had stood up to sprint? Similarly, increased muscle mass directly increases power output and inertia and indirectly increases aerodynamic-drag area. Is a bigger sprinter likely to win against a smaller sprinter with the same power-to-mass ratio? To model these scenarios, an idealized power-time data set, based on the data obtained from the road-sprint cyclist just 


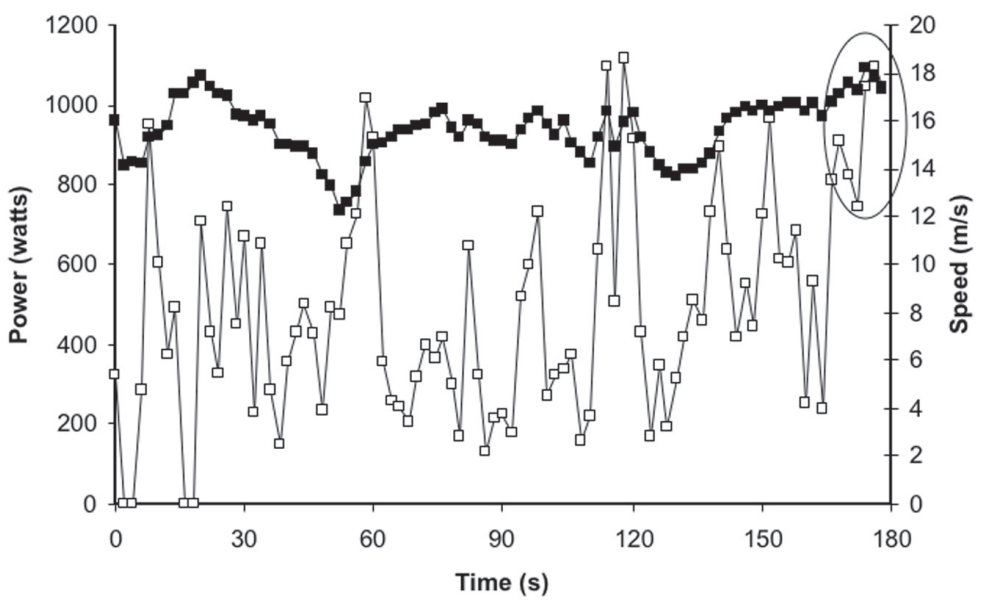

Figure 5 - Power and speed during the final 3 minutes of a pro-tour road event. Data are from the stage winner. Power $(\square)$ for the last 3 minutes averaged $490 \mathrm{~W}$ and was greater than $600 \mathrm{~W}$ for 64 seconds. The final sprint lasted 14 seconds, during which average power was $926 \mathrm{~W}$, peak power was $1097 \mathrm{~W}$, and speed (ם) increased from 16.2 to $18.1 \mathrm{~m} / \mathrm{s}(58.2$ to $65 \mathrm{~km} / \mathrm{h}$ ). The variability of power in the final minute attests to the frenzied nature of the final sprint lead-out.

described, was used. The estimated aerodynamic-drag area of that cyclist $(0.288$ $\left.\mathrm{m}^{2}\right)$ and coefficient of rolling resistance $(0.4 \%)$, mass $(80 \mathrm{~kg})$, and starting speed $(58.2 \mathrm{~km} / \mathrm{h})$ were used. The forward integration model was used to predict speed and distance for 14 seconds. The standing cyclist was assumed to produce $10 \%$ more power, but his drag area increased to $0.36 \mathrm{~m}^{2}$. The modeled "increased mass" cyclist was $10 \%$ more massive and powerful, and his drag area was increased by $7.4 \%\left(1.1^{0.75}\right)$. The model predicted that the standing cyclist would have lost a remarkable $4.1 \mathrm{~m}$ compared with his seated performance because the increase in power did not compensate for the increased aerodynamic drag. In contrast, the larger rider would have defeated his smaller counterpart by $95 \mathrm{~cm}$ because the increase in power was slightly greater than the increase in aerodynamic drag. Another factor that interactively influences power and resistance during sprint cycling is altitude. Altitude (air density) will decrease aerodynamic resistance, but the influence of altitude on fatigue in sprinting performance is not well known. Consequently, the effects of altitude will not be modeled here but remain an important area for future research.

Cyclists often take the rear position at the start of a sprint. This strategy decreases aerodynamic drag but has the disadvantage that the following cyclist must pass the leading rider to win. To model that strategy it was assumed that 2 cyclists produced the same power but one rider started $1 \mathrm{~m}$ behind the other's rear wheel ( $\sim 2.8 \mathrm{~m}$ behind the lead rider's front wheel). The drafting rider's drag area was conservatively assumed to be reduced by $25 \%{ }^{49}$ until he drew even with the lead cyclist's rear wheel and moved out of the draft. By initiating acceleration in the draft, the following rider increased speed much more rapidly, and he passed the lead rider within 8 seconds (Figure 6 ) and won by $1.05 \mathrm{~m}$ (over $236 \mathrm{~m}$ ). In this 

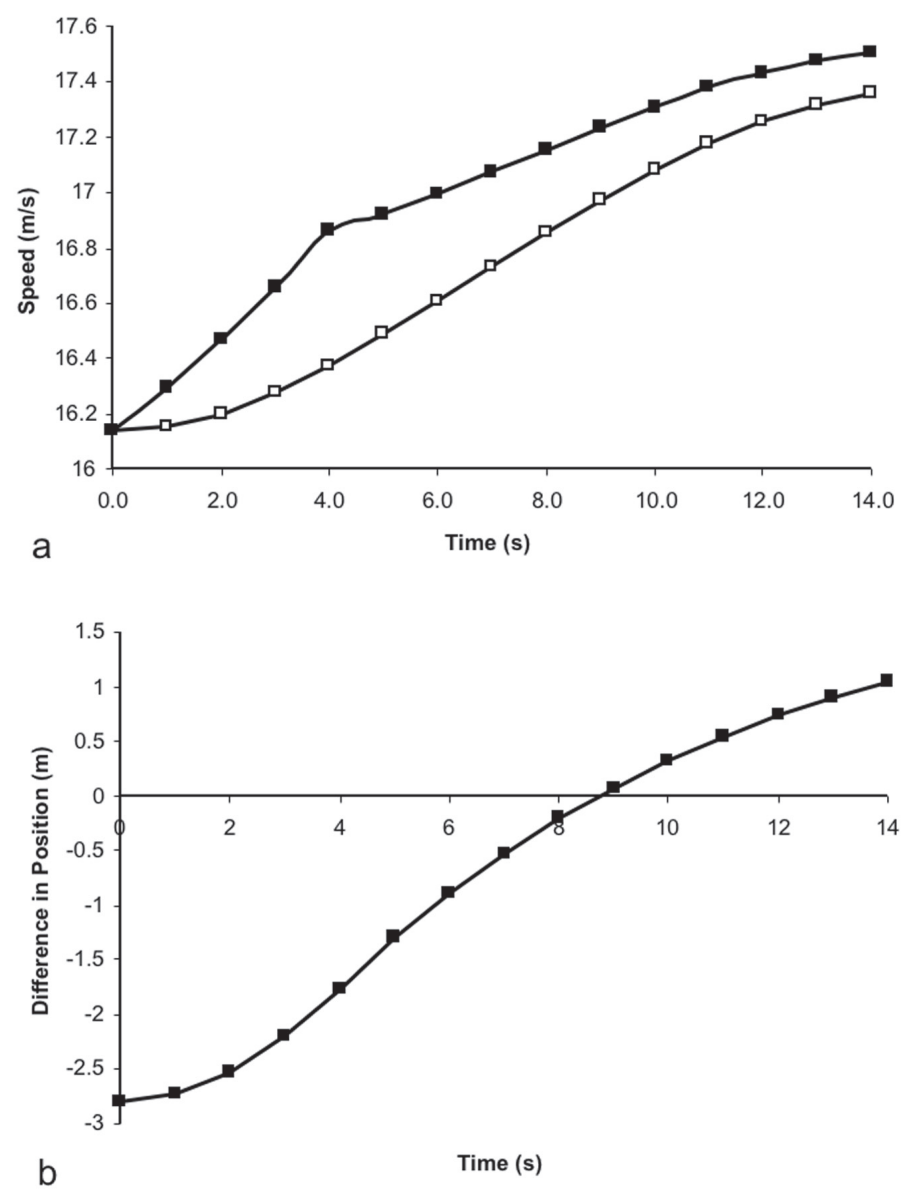

Figure 6 - The effects of drafting on sprint performance. (a) The following rider accelerates ( $\square)$ at a greater rate while drafting the lead $(\square)$ rider. (b) The greater speed attained while drafting allows him to pass and win by over $1 \mathrm{~m}$.

example a conservative but fixed reduction in aerodynamic-drag area during drafting was assumed. A more sophisticated approach could include terms for the baseline aerodynamic-drag area of both riders, the gap between the 2, and any sideways offset. This type of interactive competitive approach might be the most exciting area for advancements in performance modeling and could identify strategies for novice and world-class competitors.

\section{Summary}

Maximal cycling power is influenced by pedaling rate, muscle size and fiber composition, and fatigue. Cycling speed is resisted by aerodynamic and rolling 
friction, and any imbalance in applied versus required power results in changes in system energy. Sprinting performances arise from interaction of power production, resistance, and changes in energy. The relative contribution of the resistance and energy varies, with energy changes or acceleration dominating at low speed and aerodynamics dominating at high speed. Areas ripe for future study include improved models of drag reduction from drafting, optimization of power or pedaling rate for short time-trial efforts, interactive effects of fatigue and pedaling rate for sprints longer than 4 seconds, and maximal power reductions associated with high-altitude performance.

\section{Acknowledgments}

The authors wish to express their sincere thanks to Stefan Vogt and Olaf Schumacher for their valuable help in the preparation of this review.

\section{References}

1. Martin JC, Wagner BM, Coyle EF. Inertial-load method determines maximal cycling power in a single exercise bout. Med Sci Sports Exerc. 1997;29:1505-1512.

2. Sargeant AJ, Hoinville E, Young A. Maximum leg force and power output during short-term dynamic exercise. J Appl Physiol. 1981;51(5):1175-1182.

3. McCartney N, Heigenhauser GJ, Jones NL. Power output and fatigue of human muscle in maximal cycling exercise. J Appl Physiol. 1983;55(1):218-224.

4. Buttelli O, Seck D, Vandewalle H, Jouanin JC, Monod H. Effect of fatigue on maximal velocity and maximal torque during short exhausting cycling. Eur J Appl Physiol. 1996;73(1-2):175-179.

5. Seck D, Vandewalle H, Decrops N, Monod H. Maximal power and torque-velocity relationship on a cycle ergometer during the acceleration phase of a single all-out exercise. Eur J Appl Physiol. 1995;70(2):161-168.

6. Martin JC, Gardner AS, Barras M, Martin DT. Modeling sprint cycling using field-derived parameters and forward integration. Med Sci Sports Exerc. 2006;38(3):592-597.

7. Martin JC, Brown NA, Anderson FC, Spirduso WW. A governing relationship for repetitive muscular contraction. J Biomech. 2000;33(8):969-974.

8. Yoshihuku Y, Herzog W. Optimal design parameters of the bicycle-rider system for maximal muscle power output. J Biomech. 1990;23(10):1069-1079.

9. Hill AV. The heat of shortening and dynamic constants of muscle. Proc R Soc Lond B Biol Sci. 1938;126:136-195.

10. van Soest O, Casius LJ. Which factors determine the optimal pedaling rate in sprint cycling? Med Sci Sports Exerc. 2000;32(11):1927-1934.

11. Caiozzo VJ, Baldwin KM. Determinants of work produced by skeletal muscle: potential limitations of activation and relaxation. Am J Physiol. 1997;273(3 pt 1):C1049C1056.

12. Martin JC, Spirduso WW. Determinants of maximal cycling power: crank length, pedalling rate, and pedal speed. Eur J Appl Physiol. 2001;84(5):413-418.

13. Martin JC. Muscle power: the interaction of cycle frequency and shortening velocity. Exerc Sport Sci Rev. In press.

14. McDaniel J, Tomas A, Hunter EL, et al. Joint power distribution at 60, 90, and $120 \mathrm{rpm}$ during seated maximal cycling abstract. Med Sci Sports Exerc. 2005;37(S5):S123.

15. Akima H, Kinugasa R, Kuno S. Recruitment of the thigh muscles during sprint cycling by muscle functional magnetic resonance imaging. Int J Sports Med. 2005;26(4):245252. 
16. Pearson SJ, Cobbold M, Orrell RW, Harridge SD. Power output and muscle myosin heavy chain composition in young and elderly men. Med Sci Sports Exerc. 2006;38(9):1601-1607.

17. Swoap SJ, Caiozzo VJ, Baldwin KM. Optimal shortening velocities for in situ power production of rat soleus and plantaris muscles. Am J Physiol. 1997;273(3 pt 1):C1057C1063.

18. Hautier CA, Linossier MT, Belli A, Lacour JR, Arsac LM. Optimal velocity for maximal power production in non-isokinetic cycling is related to muscle fibre type composition. Eur J Appl Physiol. 1996;74:114-118.

19. Martin JC, Farrar RP, Wagner BM, Spirduso WW. Maximal power across the lifespan. J Gerontol A Biol Sci Med Sci. 2000;55(6):M311-M316.

20. Reiser RF, Maines JM, Eisenmann JC, Wilkinson JG. Standing and seated Wingate protocols in human cycling: a comparison of standard parameters. Eur J Appl Physiol. 2002;88(1-2):152-157.

21. Davidson CJ, Wagner BM, Martin JC. Seated and standing maximal neuromuscular cycling power [abstract]. Med Sci Sports Exerc. 2004;36(5S):S344.

22. Davidson CJ, Horscroft RD, McDaniel J, et al. The biomechanics of producing standing and seated maximal cycling power [abstract]. Med Sci Sports Exerc. 2005;37(S5): S393.

23. Beelen A, Sargeant AJ. Effect of fatigue on maximal power output at different contraction velocities in humans. J Appl Physiol. 1991;71(6):2332-2337.

24. Bar-Or O, Dotan R, Inbar O. A 30-second all-out ergometric test: its reliability and validity for anaerobic capacity. Isr J Med Sci. 1977;13:126.

25. Maud PJ, Shultz BB. Norms for the Wingate anaerobic test with comparison to another similar test. Res Q Exerc Sport. 1989;60(2):144-151.

26. Jones NL, McCartney N, Graham T, et al. Muscle performance and metabolism in maximal isokinetic cycling at slow and fast speeds. J Appl Physiol. 1985;59(1):132-136.

27. Craig NP, Pyke FS, Norton KI. Specificity of test duration when assessing the anaerobic lactacid capacity of high-performance track cyclists. Int J Sports Med. 1989;10(4):237-242.

28. Bundle MW, Ernst CL, Bellizzi MJ, Wright S, Weyand PG. A metabolic basis for impaired muscle force production and neuromuscular compensation during sprint cycling. Am J Physiol Regul Integr Comp Physiol. 2006;291(5):R1457-R1464.

29. Medbo JI, Tabata I. Relative importance of aerobic and anaerobic energy release during short-lasting exhausting bicycle exercise. J Appl Physiol. 1989;67(5):1881-1886.

30. Weyand PG, Lin JE, Bundle MW. Sprint performance-duration relationships are set by the fractional duration of external force application. Am J Physiol Regul Integr Comp Physiol. 2006;290(3):R758-R765.

31. Watt KK, Hopkins WG, Snow RJ. Reliability of performance in repeated sprint cycling tests. J Sci Med Sport. 2002;5(4):354-361.

32. Mendez-Villanueva A, Bishop D, Hamer P. Reproducibility of a 6-s maximal cycling sprint test. J Sci Med Sport. 2006 Aug 31.

33. Martin JC, Diedrich D, Coyle EF. Time course of learning to produce maximum cycling power. Int J Sports Med. 2000;21(7):485-487.

34. Glaister M, Stone MH, Stewart AM, Hughes M, Moir GL. The influence of recovery duration on multiple sprint cycling performance. J Strength Cond Res. 2005;19(4):831-837.

35. Buttelli O, Vandewalle H, Jouanin JC. Recovery of the torque-velocity relationship after short exhausting cycling exercise. Eur J Appl Physiol Occup Physiol. 1999;80(3):249-251.

36. Bogdanis GC, Nevill ME, Lakomy HK, Graham CM, Louis G. Effects of active recovery on power output during repeated maximal sprint cycling. Eur J Appl Physiol Occup Physiol. 1996;74(5):461-469.

37. Fritzsche RG, Switzer TW, Hodgkinson BJ, Lee SH, Martin JC, Coyle EF. Water and carbohydrate ingestion during prolonged exercise increase maximal neuromuscular power. J Appl Physiol. 2000;88(2):730-737. 
38. Drust B, Rasmussen P, Mohr M, Nielsen B, Nybo L. Elevations in core and muscle temperature impairs repeated sprint performance. Acta Physiol Scand. 2005;183(2):181190.

39. Castle PC, Macdonald AL, Philp A, Webborn A, Watt PW, Maxwell NS. Precooling leg muscle improves intermittent sprint exercise performance in hot, humid conditions. $J$ Appl Physiol. 2006;100(4):1377-1384.

40. Ball TC, Headley SA, Vanderburgh PM, Smith JC. Periodic carbohydrate replacement during $50 \mathrm{~min}$ of high-intensity cycling improves subsequent sprint performance. Int J Sport Nutr. 1995;5(2):151-158.

41. Rockwell MS, Rankin JW, Dixon H. Effects of muscle glycogen on performance of repeated sprints and mechanisms of fatigue. Int J Sport Nutr Exerc Metab. 2003;13(1):1-14.

42. Husak JF, Fox SF, Lovern MB, Van Den Bussche RA. Faster lizards sire more offspring: sexual selection on whole-animal performance. Evolution Int J Org Evolution. 2006;60(10):2122-2130.

43. di Prampero PE, Cortili G, Mognoni P, Saibene F. Equation of motion of a cyclist. $J$ Appl Physiol. 1979;47(1):201-206.

44. Olds TS, Norton KI, Craig NP. Mathematical model of cycling performance. J Appl Physiol. 1993;75(2):730-737.

45. Martin JC, Milliken DL, Cobb JE, McFadden KL, Coggan AR. Validation of a mathematical model for road cycling power. J Appl Biomech. 1998;14(3):276-291.

46. Bassett DR Jr, Kyle CR, Passfield L, Broker JP, Burke ER. Comparing cycling world hour records, 1967-1996: modeling with empirical data. Med Sci Sports Exerc. 1999;31(11):1665-1676.

47. Potter MC, Foss JF. Fluid Mechanics. Okemos, Mich: Great Lakes Press; 1982.

48. Olds TS, Norton KI, Lowe EL, Olive S, Reay F, Ly S. Modeling road-cycling performance. J Appl Physiol. 1995;78(4):1596-1611.

49. Kyle CR. Reduction of wind resistance and power output of racing cyclists and runners traveling in groups. Ergonomics. 1979;22(4):387.

50. Zdravkovich MM, Ashcroft MW, Chisholm SJ, Hicks N. Effect of cyclists' posture and vicinity of another cyclists on aerodynamic drag. In: Haake S, ed. The Engineering of Sport. Rotterdam, The Netherlands: Swets \& Zeitlinger; 1996:356.

51. Dorel S, Hautier CA, Rambaud O, et al. Torque and power-velocity relationships in cycling: relevance to track sprint performance in world-class cyclists. Int J Sports Med. 2005;26(9):739-746.

52. Heil DP. Body mass scaling of frontal area in competitive cyclists not using aerohandlebars. Eur J Appl Physiol. 2002;87(6):520-528.

53. Kyle CR. Energy and aerodynamics in bicycling. Clin Sports Med. 1994;13(1):3973.

54. Greenwell DI, Wood NJ, Bridge EKL, Addy RJ. Aerodynamic characteristics of lowdrag bicycle wheels. Aeronaut J. 1995;99(983):109-120.

55. Tew GS, Sayers AT. Aerodynamics of yawed racing cycle wheels. Wind Eng Ind Aerodynamics. 1999;82(1-3):209-222.

56. Broker JP, Kyle CR, Burke ER. Racing cyclist power requirements in the 4000-m individual and team pursuits. Med Sci Sports Exerc. 1999;31(11):1677-1685.

57. Dahn K, Mai L, Poland J, Jenkins C. Frictional resistance in bicycle wheel bearings. Cycling Sci. 1991(Dec and Sept):28-32.

58. Martin JC, Gardner AS, Barras M, Martin DT. Power, pedaling rate, and fatigue during the 200 meter time trail performance [abstract]. Med Sci Sports Exerc. 2005;37(5S): S85-S86.

59. Gardner AS, Martin DT, Barras M, Jenkins DG, Hahn AG. Power output demands of elite track sprint cycling. Int J Perf Anal Sport. 2005;5:149-154.

60. Martin JC, Cobb JE, Jeukendrup AE. Body position and aerodynamics. In: Jeukendrup AE, ed. High Performance Cycling. Champaign, Ill: Human Kinetics; 2002:103-112. 